\title{
O software Atlas.ti como recurso para a análise de conteúdo: analisando a robótica no Ensino de Ciências em teses brasileiras
}

\section{Atlas.ti software as a resource for content analysis: analyzing robotics in science teaching in Brazilian theses}

\author{
Luiz Alberto Silva Junior ${ }^{1}$ \\ https://orcid.org/0000-0001-5336-5212 \\ Marcelo Brito Carneiro Leão ${ }^{1}$
}

\begin{abstract}
Resumo: Este trabalho se propõe a apresentar a utilização do software Atlas.ti como recurso para a realização das técnicas da Análise de Conteúdo de Bardin. Para isso, utilizamos como marco metodológico a revisão sistemática das teses brasileiras que se debruçam sobre o uso da robótica educacional no ensino de ciências. Descrevemos, a partir dos dados levantados na Biblioteca Digital de Teses e Dissertações, os caminhos no software para conduzir as etapas de pré-análise, exploração do material e inferências. Diante disso, foi possível identificar tendências e lacunas da pesquisa brasileira em nível de doutorado sobre o foco temático, tendências essas que foram discutidas nas quatro categorias empíricas de análise: base epistemológica, inconsistência metodológica, público alvo e características da produção nacional. Após as inferências, foi possível compreender o escopo das teses brasileiras, bem como concluir que o software representa um recurso tecnológico satisfatório para cumprir todas as etapas da análise de conteúdo.
\end{abstract}

Palavras-chave: Software Atlas.ti. Análise de conteúdo. Revisão de literatura. Robótica educacional. Ensino de ciências.

\begin{abstract}
This paper presents the use of the Atlas.ti software as a resource to the realization of the Bardin's Content Analysis. For this, we use as a methodological framework the systematic review of the Brazilian doctoral theses that study the use of educational robotics in science education. We describe, from the data collected in the Digital Library of Thesis and Dissertations, the commands in the software to conduct the steps of pre-analysis, material exploration and inferences. With this, was possible to identify trends and gaps in Brazilian research at the doctoral level on the thematic focus, which were discussed in the four empirical categories of analysis: Epistemological basis, Methodological inconsistency, Target audience and Characteristics of national production. After the inferences, it was possible to understand the scope of the Brazilian theses. As well, we concluded that the software is a satisfactory technological resource to carry out all the steps of Content Analysis.
\end{abstract}

Keywords: Atlas.ti software. Content analysis. Literature review. Educational robotics. Science education.

\footnotetext{
${ }^{1}$ Universidade Federal Rural de Pernambuco (UFRPE), Programa de Pós-Graduação em Ensino de Ciências, Recife, PE, Brasil. E-mail: <junior_mineiros@hotmail.com>.
} 


\section{Introdução}

A evolução científico-tecnológica dos últimos dois séculos provocou importantes avanços em todos os campos de conhecimento da sociedade. Sobretudo no que dizem respeito às tecnologias, elas influenciaram o modo de vida e de relacionamento social, reorganizaram as estruturas sociais e exigiram novas formas de pensar sobre o ser humano e sua relação com o meio e com o outro. Alguns autores apontam para o intenso poder de penetração das tecnologias digitais na vida das pessoas e no seu cotidiano, modificando as relações e implicando em novas culturas. Como exemplo, Branco (2011) pondera que as inovações tecnológicas estão intrinsecamente relacionadas com a mudança cultural das sociedades.

Nesse sentido, o uso dos recursos tecnológicos também tem modificado a educação e a ciência em geral, desde o desenvolvimento de novas técnicas até a modernização dos métodos já existentes. Pensando especificamente na área acadêmica, diversas contribuições têm alterado e acelerado o processo de investigação científica.

Dessa forma, pretende-se trabalhar neste artigo a apresentação e discussão do uso de um software para análise qualitativa de dados, sendo suportado pelas técnicas metodológicas da Análise de Conteúdo (AC) de Bardin (1970), a ser discutida na seção metodologia. É importante destacar que o software e a AC podem ser empregados em um variado leque de pesquisas em diversas áreas do conhecimento. A compreensão da teoria e da manipulação do software permite ao pesquisador adequar qualquer tipo de pesquisa científica dentro dos parâmetros ora elencados.

O Atlas.ti é um software para análise de dados qualitativos desenvolvido em 1989 por Thomas Muhr, na Alemanha. Ele tem sido utilizado, desde então, por pesquisadores do mundo todo por conta de sua facilidade e da gama de ferramentas disponíveis (MUHR, 1991). Pode ser utilizado em duas versões: versão $P R O$, adquirindo a licença anual no portal da companhia Atlas.ti $\mathrm{GmbH}$ ou versão trial, com todas as funcionalidades ativas, contudo com limite para a criação de conteúdo. A versão 8 é a mais atual, a qual utilizamos nesse trabalho. Dentre suas diversas funcionalidades está a possibilidade de construir estados da arte, análise multimídia de imagens, áudios e vídeos, tratamento estatístico de dados, análise de surveys, codificação de base de dados e, como propomos neste artigo, a sistematização de todas as etapas da AC.

É importante ressaltar que o Atlas.ti é uma ferramenta que auxilia o pesquisador no processo de organização da análise dos dados, mas que o software não faz a análise sozinho. Todas as inferências e categorizações devem ser feitas pelo pesquisador, suportado pela sua base teórica. A eficiência do software está como diz Hwang (2008), na interface entre a expertise humana e o processamento de dados do computador.

Seu idealizador baseou-se na Grounded Theory para desenvolver o programa e visou, inicialmente, a pesquisa social e linguística, mas reconheceu que ele poderia ser utilizado por outras áreas (MUHR, 1991). De fato, muitos pesquisadores de diversas áreas têm utilizado o Atlas.ti em suas análises, confirmando o potencial abrangente do software nas mais diversas áreas do conhecimento.

Uma vez esclarecido o software Atlas.ti como o plano de frente deste artigo, nos apoiaremos, como plano de fundo, numa revisão sistemática da literatura de teses brasileiras sobre o

\footnotetext{
${ }^{2}$ Informação sobre o software disponível em: <https://atlasti.com/>. Acesso em: 20 ago. 2018. 
uso da robótica educacional. A partir dessa temática, realizaremos as etapas da AC através do software e discutiremos sua usabilidade.

Guiados pela questão de pesquisa como a robótica educacional aplicada ao ensino de ciências tem sido discutida nas teses produzৃidas no Brasil?, realizamos uma análise da produção nacional acerca desse tema.

Nesse sentido, nosso objetivo foi apresentar a utilização do software Atlas.ti como recurso para a realização das técnicas da Análise de Conteúdo de Bardin, por meio de uma revisão sistemática da literatura de teses publicadas no Brasil sobre o uso da robótica educacional no ensino de ciências. Sendo assim, apresentaremos detalhadamente, na sequência, a instrumentalização do software para a análise, tendo como plano de fundo a revisão das teses sobre robótica educacional.

\section{Metodologia $^{3}$}

O caminho metodológico desse trabalho foi conduzido de acordo com as orientações de uma revisão sistemática da literatura propostas por Silva (2009). Adicionalmente, nos baseamos, também, nos procedimentos de seleção, exploração e inferência dos resultados da Análise de Conteúdo (BARDIN, 1970). De acordo com Silva (2009, p. 78), os passos para a condução da revisão sistemática estão descritos a seguir.

1. Definição da questão de pesquisa: a questão norteadora de pesquisa (como a robótica educacional aplicada ao ensino de ciências tem sido discutida nas teses produzidas no Brasil?) foi elaborada a partir da necessidade inicial de se conhecer o campo de produções dentro da temática robótica educacional para a realização de uma pesquisa de doutorado ligada ao ensino de ciências.

2. Escopo da revisão: realizar uma revisão sistemática da literatura de teses publicadas no Brasil sobre o uso da robótica educacional no ensino de ciências, sendo suportada pelo software Atlas.ti e pela Análise de Conteúdo de Lawrence Bardin.

3. Conduzir a revisão:

- Todos os papers: para a construção do corpus de dados a serem analisados, exploramos a Biblioteca Digital de Teses e Dissertações (BDTD) do Instituto Brasileiro de Informação em Ciência e Tecnologia (IBICT). Para cumprir a Regra da Exaustividade de Bardin, buscamos com a palavra-chave "robótica" e marcamos o filtro "tese", tendo a busca inicial retornado 204 produções. Vale ressaltar que não delimitamos um período de tempo para a busca, pois nosso objetivo foi localizar todas as teses brasileiras publicadas na BDTD. Sendo assim, as datas variaram de 1991 (a mais antiga no portal) até 2016 (a mais recente).

\footnotetext{
${ }^{3}$ Parte dessa metodologia foi apresentada, em caráter preliminar, no X Congreso Internacional sobre Investigación en Didáctica de las Ciencias, na cidade de Sevilha, Espanha, de 5 a 8 de setembro de 2017. Os autores agradecem as contribuições surgidas na ocasião do debate que proporcionaram a ampliação do trabalho neste artigo.
} 
- Screening dos papers: O autor chama de screening o critério prático de visualização dos papers. Nesse sentido, utilizamos como critério os títulos das teses, independente de data, instituição ou outro dado sobre o documento.

- Papers relevantes: A fim de filtrar as teses que apresentassem conteúdo relacionado à robótica educacional procedemos com a seleção a partir da leitura dos títulos das 204 teses, utilizando como critério de exclusão aquelas produções que não tinham foco educacional ou pedagógico (e. g. tese sobre braço mecânico para agricultura). Foram promovidas doze teses para o próximo critério de inclusão, cumprindo assim a Regra da Representatividade descrita em Bardin.

- Keywording nos resumos: O passo seguinte foi a identificação das teses ligadas ao ensino de ciências a partir da leitura dos resumos e sumário. Ao compilar todas as teses ligadas ao objetivo do trabalho cumprimos a Regra da Pertinência da AC. Após isso, o corpus de dados foi formado com 8 teses sobre a robótica educacional no ensino de ciências, as quais estão descritas no Quadro 1.

Quadro 1. Teses selecionadas para a análise

\begin{tabular}{|c|l|l|l|l|c|}
\hline Tese & Pesquisador & Instituição & \multicolumn{1}{c|}{ Orientador } & \multicolumn{1}{c|}{ Programa } & Ano \\
\hline T1 & Barbosa & UFU & Arlindo J. Souza Junior & Educação & 2016 \\
\hline T2 & Barros Neto & PUCSP & Gerson P. Oliveira & Educação Matemática & 2015 \\
\hline T3 & Schivani & USP & Maurício Pietrocola & Educação & 2014 \\
\hline T4 & César & UFBA & Teresinha F. Burnham & Difusão do conhecimento & 2013 \\
\hline T5 & Campos & PUCSP & Maria E. B. Almeida & Educação & 2011 \\
\hline T6 & Silva & UFRN & Ana M. G. Guerreiro & Engenharia Elétrica & 2009 \\
\hline T7 & Santana & UFBA & Teresinha F. Burnham & Educação & 2009 \\
\hline T8 & Lopes & UFRGS & Léa C. Fagundes & Informática na Educação & 2008 \\
\hline
\end{tabular}

Fonte: elaborado pelos autores.

- Esquema de classificação: As teses foram extraídas do portal no formato .PDF e adicionadas ao software Atlas.ti em um arquivo novo que no programa recebe o nome de Hermenentic Unit (Unidade hermenêutica). Cada tese foi identificada por uma sigla de T1 a T8.

- Processo de extração de dados e mapeamento: Para a pré-análise dos dados, iniciamos com a leitura flutuante dos capítulos teóricos e metodológicos das teses, tal qual explica Bardin. Essa leitura permitiu a primeira identificação dos trabalhos por proximidade de assuntos, promovendo, ainda, as primeiras hipóteses. A partir dessas primeiras impressões, uma segunda leitura minuciosa permitiu a referenciação, processo descrito na AC como a elaboração de índices e indicadores. Os índices são os termos, palavras, expressões que se destacam na leitura, enquanto que a sua frequência se chama indicador. Dentro do Atlas.ti, no decorrer do texto é possível criar codes (códigos), que são termos destacados e marcados no ponto original do arquivo PDF. Com a repetição dos códigos, o software levanta sua frequência de aparição ao longo do texto. Dessa forma, os códigos no software representam os índices da AC, ao passo que o próprio software calcula o indicador para cada índice. 
O software Atlas.ti como recurso para a análise de conteúdo: ...

No processo de referenciação foram criados 14 índices que traziam informações relevantes para a análise das tendências nas teses. Esses índices foram marcados nos textos dentro do Atlas.ti por meio dos códigos e identificados com um conjunto de duas ou três letras iniciais para que pudessem ser resgatados posteriormente. Os 14 índices estão no Quadro 2.

Quadro 2. Índices criados durante a pré-análise

\begin{tabular}{|l|l|}
\hline RE & Referências: Seleção dos principais referenciais teóricos utilizados na tese. \\
\hline EPI & Epistemologia: Demarcação do arcabouço epistemológico que guiou a tese. \\
\hline DEF & Definição de robótica: Olhar para o termo utilizado (se pedagógica, educacional, etc.). \\
\hline FP & Formação de professores: Aspectos ligados à formação de professores. \\
\hline PPG & Programa de Pós: Programa de Pós-Graduação em que a pesquisa foi desenvolvida. \\
\hline NAT & Natureza da pesquisa: Seleção do tipo de pesquisa descrito na metodologia. \\
\hline QP & Questão de pesquisa: Trechos destacados na questão de pesquisa que orientou a pesquisa. \\
\hline IN & Instrumentos: Destaque dos instrumentos utilizados para a construção dos dados. \\
\hline LOC & Local da pesquisa: Referência ao espaço onde a pesquisa foi realizada. \\
\hline SUJ & Sujeitos: Demarcação dos sujeitos envolvidos na pesquisa. \\
\hline AN & Análise: Referência ao método de análise de dados. \\
\hline AD & Atividades didáticas: Atividades realizadas com a robótica na investigação. \\
\hline UNI & Universidade: Codificação da universidade onde se situa o Programa de Pós-graduação. \\
\hline MAT & Material de robótica: Descrição do tipo de recurso robótico utilizado. \\
\hline
\end{tabular}

Fonte: Elaborado pelos autores.

O processo de codificação é importante na AC, pois permite identificar aspectos que parecem importantes na pré-análise, mas que nem sempre serão utilizados na categorização. Portanto, é interessante sempre produzir um resumo tal como o Quadro 2 para que os significados dos códigos que geraram os índices possam ser retomados em outro momento, até para compreensão do próprio pesquisador.

Um dos pontos positivos de se realizar a análise dentro do software, é que na Unidade Hermenêutica criada com as 8 teses, o texto delas aparece de forma contínua e é possível produzir códigos em qualquer uma delas. Isso facilita o processo porque permite ir e voltar entre os textos, criar e repetir códigos entre teses diferentes e o software fará a contagem da frequência de códigos em todas elas, sem precisar do trabalho manual do pesquisador, otimizando o tempo de pesquisa.

Após a referenciação, todos os códigos foram organizados em grupos denominados Family (família), configurando como pré-categorias de análise. Esse processo é realizado no layout demonstrado na Figura 1. Como se observa, no canto inferior direito da tela se encontram todos os códigos construídos ao longo das 8 teses analisadas (foram criados 132 códigos divididos entre os 14 índices do Quadro 2). Em cada um deles existe um par ordenado do tipo $\{x-y\}$, onde $\mathrm{x}$ representa o indicador (a frequência que esse mesmo código aparece ao longo dos 8 trabalhos) e y representa o número de ligações desse código com outro código (funcionalidade não utilizada nesse momento, por isso todos possuem y=0). Por exemplo, o código "AD:Oficinas $\{4-0\} "$ significa que 4 teses utilizaram oficinas como atividades didáticas. 
Figura 1. Organização dos códigos em famílias

\begin{tabular}{l|l|l|l|l|l|l|l}
\hline & Name & Size Modified by & Created & Modified \\
\hline$\ll$ & Definição de robótica & 4
\end{tabular}

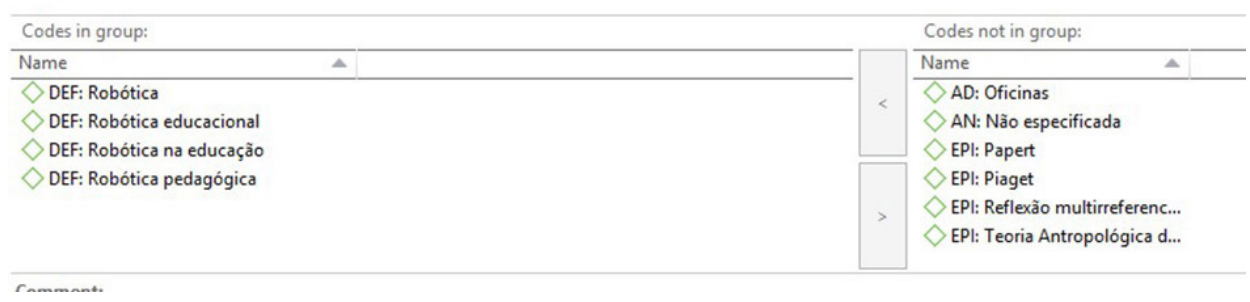

Fonte: elaborado pelos autores

No lado esquerdo superior está uma das famílias (pré-categoria - definição de robótica) criada a partir das primeiras hipóteses ao dirigir a codificação das teses (o software representa uma família com dois losangos) e no lado esquerdo inferior aparecem os códigos que foram adicionados nessa família (DEF: Robótica, DEF: Robótica educacional, DEF: Robótica na educação, DEF: Robótica pedagógica). Na figura 1 inserimos 4 códigos na família (pré-categoria) Definição de robótica.

Quando organizamos todos os códigos em famílias, iniciamos a análise desses para selecionar quais índices seriam utilizados ou reformulados para dar prosseguimento à construção das categorias propriamente ditas. Para isso, o software apresenta uma funcionalidade chamada network (rede), onde os códigos e famílias podem ser organizados numa rede semântica semelhante a um mapa mental, permitindo melhor visualização do material produzido. A organização dos códigos depende da leitura do analista e do seu referencial teórico. Nesse sentido, organizamos os códigos na rede a partir da aproximação deles e da forma como entendemos seu agrupamento em pré-categorias semelhantes que foram emergindo durante a análise.

A Figura 2 representa uma parte da network, onde são exibidas as pré-categorias Definição de robótica e Epistemologia. Para a primeira, estão associados quatro índices encontrados nas teses analisadas, indicando que 3 das 8 teses utilizam o termo robótica educacional, outras 3 utilizam robótica pedagógica, 1 utiliza robótica na educação e a última utiliza apenas robótica. Para a segunda pré-categoria, foram associados 6 diferentes índices, cujos indicadores mostram uma heterogeneidade de pressupostos epistemológicos nas teses analisadas. Uma funcionalidade do Atlas.ti nas redes é de mostrar os códigos com cores diferentes, de acordo com a frequência que foram marcados nos textos. Isso permite um olhar amplo sobre quais códigos foram mais utilizados e quais foram pouco utilizados.

A partir dessa rede, foi possível observar quais os índices relevantes e quais os que traziam poucas informações ou não se traduziam em tendências de pesquisa. Diante disso, excluímos os índices "formação de professores" e "questão de pesquisa". O primeiro porque 
só aparecia em duas teses e o segundo porque apresentava muita multiplicidade de temas, impossibilitando a identificação de uma tendência em todas as teses. Adicionalmente, os índices "programa de pós-graduação" e "universidade" foram exportados para o Microsoft Word para a construção de gráficos e tabelas, não sendo utilizados na análise posterior no software. Feito isso, retornamos aos documentos para uma nova leitura e identificação de unidades de registro e contexto.

Figura 2. Rede dos índices e pré-categorias
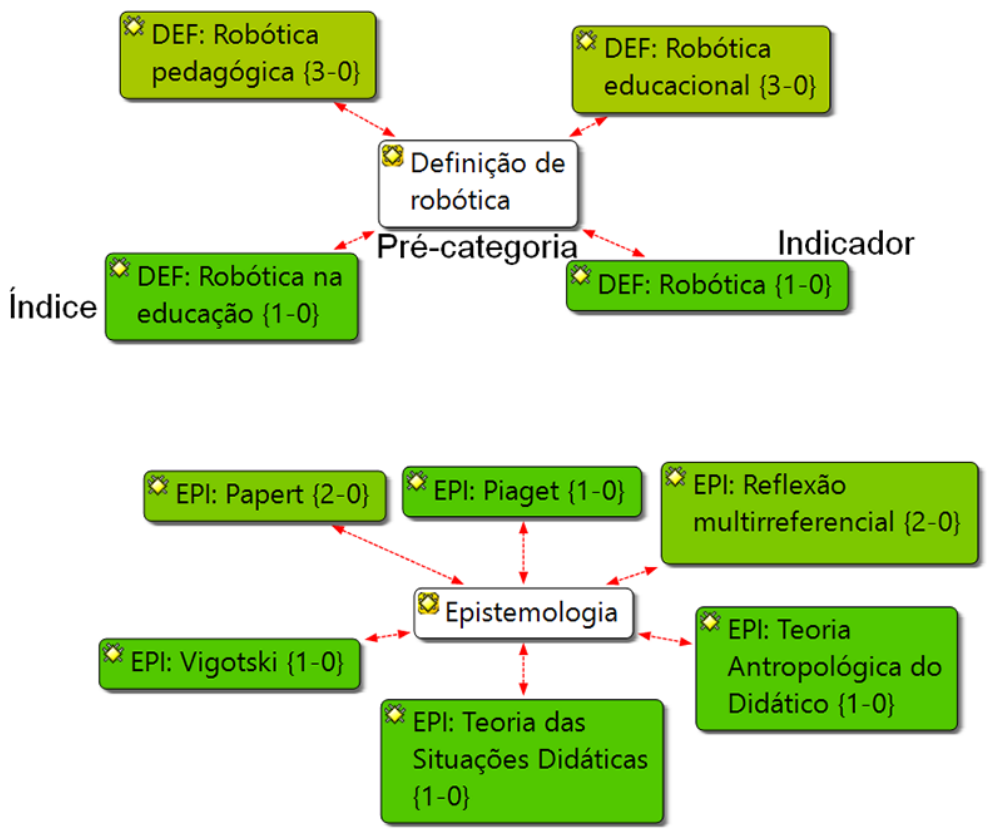

Fonte: Elaborado pelos autores.

$\mathrm{Na}$ etapa seguinte foi realizada a criação das unidades de registro a partir de temas e/ou palavras relevantes levantadas a partir dos índices. No software, extraímos trechos que são marcados dentro do próprio texto, permitindo a sua localização posterior. De acordo com Bardin (1970), para que uma unidade de registro faça sentido é preciso explicitar o contexto em que ela está. A seleção de um trecho imediatamente anterior e/ou posterior é chamada de unidade de contexto. No Atlas.ti, o procedimento é semelhante aos códigos, tendo como nomenclatura o termo quotation (citação). Assim, foram marcados no texto os códigos e as citações que representam, respectivamente, as unidades de registro e as unidades de contexto, conforme explicita a Figura 3. 
Figura 3. Unidades de registro (códigos) e unidades de contexto (citação)

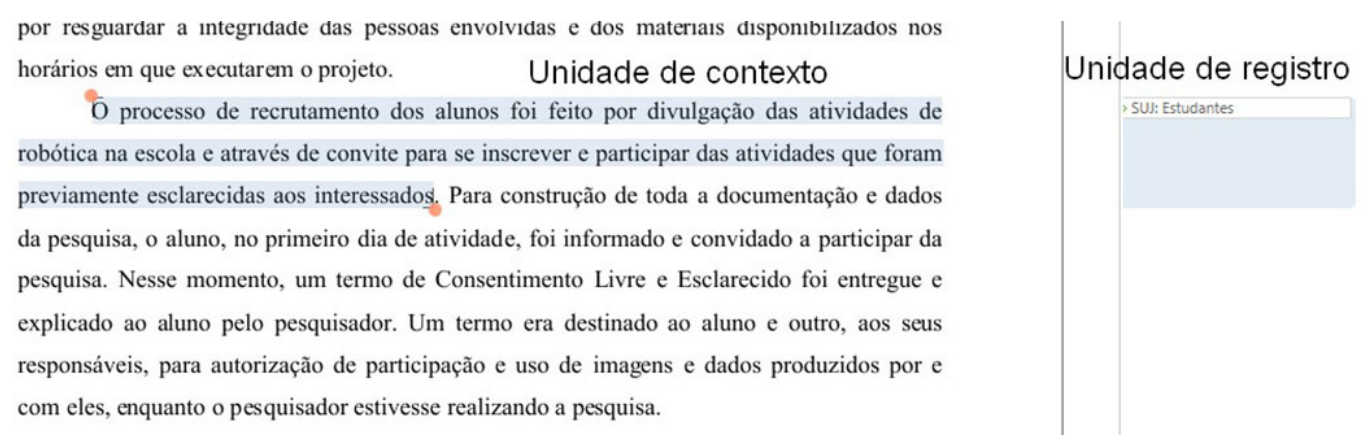

Fonte: Elaborada pelos autores.

No layout do Atlas.ti, onde o lado esquerdo representa o texto em análise (no caso uma das teses) e o lado direito destaca os códigos e citações criados a partir do texto. No trecho da tese em análise, criamos a unidade de registro "Teoria das situações didáticas" dentro do índice "Epistemologia". Ou seja, entendemos que a base epistemológica dessa tese é a teoria supracitada. Contudo, para que isso faça sentido tanto para o leitor quanto para o analista, Bardin recomenda extrair o contexto em que a unidade de registro foi estabelecida, para que não haja dúvidas sobre a análise. Dessa forma, destacamos o trecho no software (trecho grifado no lado esquerdo) e criamos ali uma citação (identificada do lado direito pela barra cinza ao lado da unidade de registro). Assim, o pesquisador pode o tempo todo localizar no texto as unidades que ele próprio criou, bem como revisar qual foi o seu critério para essa criação observando a unidade de contexto que gerou aquele registro. Essa é outra vantagem do software frente a análise manual.

Para deixar mais claro o processo de criação de unidades de registro e unidades de contexto, trazemos alguns exemplos no Quadro 3, onde a primeira coluna mostra trechos das teses analisadas (as unidades de contexto) e a segunda coluna mostra as unidades de registro que foram criadas e serão utilizadas na próxima etapa de categorização.

Posteriormente, construímos outra rede para associar as unidades de registro em categorias do modo que está apresentado na Figura 4.

As quatro categorias empíricas construídas foram: Base epistemológica, Público-alvo, Inconsistência metodológica e Características da produção nacional. Conforme Bardin (1970), categoria empírica é aquela que emerge dos dados. Logo, essas categorias surgiram após as sucessivas organizações de códigos, famílias e citações que realizamos no software Atlas.ti. Como mostra a Figura 4, agrupamos as unidades de registro referentes à epistemologia (EPI) e Referências (RE) dentro da categoria "Base epistemológica", pois compreendemos que esses são os principais autores utilizados nas teses analisadas. Da mesma forma, os registros de sujeitos (SUJ) e local onde a pesquisa foi realizada (LOC) contemplaram a categoria "Público-alvo", permitindo inferir que, nas 8 teses, o principal público-alvo das pesquisas foram estudantes, professores e gestores do ensino médio e fundamental. Para construir a categoria "inconsistência metodológica" agrupamos registros de 5 teses que não definiram qual o método de análise dos dados, 6 registros de teses que se pautaram na observação participante como metodologia 
e outras 3 que utilizaram também questionários. De posse dessa organização, definimos como inconsistência a variedade de abordagens teóricas e metodológicas nas teses e a pouca comunicação entre elas. Por último, elencamos nessa rede aspectos característicos das 8 teses de modo geral, como o principal material de robótica utilizado (Lego), os principais Programas de Pósgraduação (PPG) onde as pesquisas foram dirigidas (Doutorado em Educação), a referência mais citada (D’Abreu). Assim, criamos a categoria “tendências da produção nacional”.

Quadro 3. Exemplos de unidades de contexto e unidades de registro

\begin{tabular}{|l|l|}
\hline \multicolumn{1}{|c|}{$\begin{array}{c}\text { Unidades } \\
\text { de contexto }\end{array}$} & \multicolumn{1}{|c|}{$\begin{array}{c}\text { Unidades } \\
\text { de registro }\end{array}$} \\
\hline $\begin{array}{l}\text { "A partir do processo de análise dos dados produzimos três eixos com marcas } \\
\text { atravessadas de paixão, de incerteza, de singularidade, ou seja, saberes pela } \\
\text { experiência [...]" }\end{array}$ & $\begin{array}{l}\text { AN: Análise não } \\
\text { especificada }\end{array}$ \\
\hline $\begin{array}{l}\text { "Com base na Epistemologia Genética de Lean Piaget, o presente trabalho } \\
\text { procura contribuir para a produção de conhecimento na área de concentração das } \\
\text { ciências cognitivas aplicada à Informática na Educação [...]" }\end{array}$ & EPI: Piaget \\
\hline $\begin{array}{l}\text { "Ainda assim, não temos a pretensão de defender um conceito ou dizer que } \\
\text { um é mais correto que o outro, mas em nosso entendimento e para nossa } \\
\text { pesquisa faremos uso da expressão robótica na educação, pois compreendemos } \\
\text { que a robótica é um recurso tecnológico usado na educação básica para o } \\
\text { desenvolvimento de projetos relacionados às seguintes categorias [...]" }\end{array}$ & $\begin{array}{l}\text { DEF: Robótica } \\
\text { na educação }\end{array}$ \\
\hline $\begin{array}{l}\text { "Utilizaremos, nesta pesquisa, os hardwares Arduino, Pinguino e a Interface de } \\
\text { Hardware Livre (IHL) - que, apesar de não possuírem todos os componentes } \\
\text { eletroeletrônicos livres, são chamados de hardwares livres [...]" }\end{array}$ & $\begin{array}{l}\text { MAT: Arduino } \\
\text { MAT: Pinguino } \\
\text { MAT: IHL }\end{array}$ \\
\hline
\end{tabular}

Fonte: elaborado pelos autores.

Figura 4. Categorias empíricas
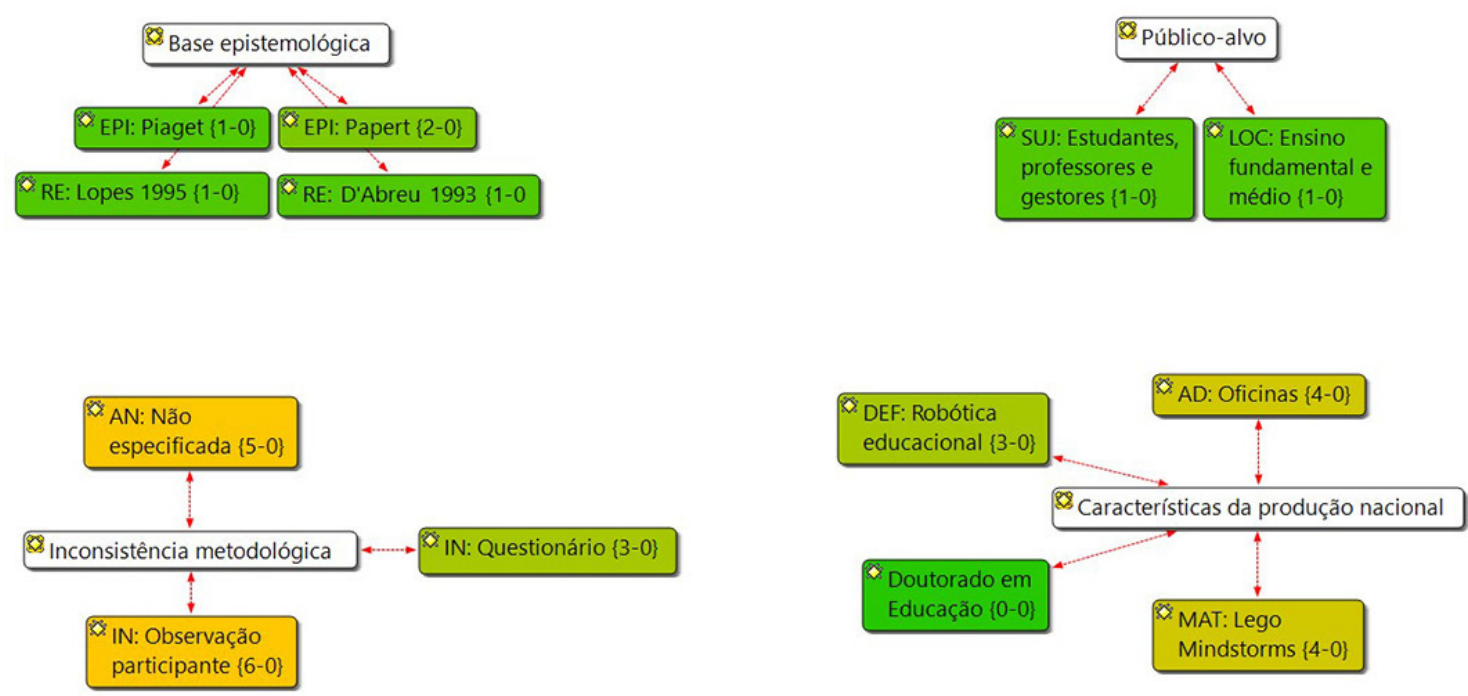

Fonte: elaborado pelos autores. 


\section{Resultados e discussão}

A fim de sintetizar todo o procedimento desenvolvido com o Atlas.ti e a Análise de Conteúdo, relacionamos no Quadro 4 os objetivos, os métodos de análise no software e a correlação com os pressupostos da AC para facilitar o entendimento de todo o caminho metodológico, além de permitir novos olhares e abordagens para a interface entre Atlas.ti e Análise de Conteúdo.

Adicionalmente, reiteramos que o Atlas.ti não conduz a análise sozinho. Todas as relações que fizemos entre códigos e famílias, a passagem dos índices para as unidades de registro e depois para as categorias, a organização das redes e toda a discussão subsequente é devida ao arcabouço teórico do pesquisador. O software contribui para a organização dos dados, a otimização do processo analítico, além de ser maleável para inúmeros tipos de pesquisas qualitativas com objetivos diversos.

A partir do Quadro 4, correlacionamos as 3 etapas da AC com os processos conduzidos no Atlas.ti para alcançar os objetivos propostos pela revisão sistemática da literatura, que ora adotamos como plano de fundo para discutir a interface software-Análise de Conteúdo.

Dentro da Pré-análise foi necessário realizar algumas etapas. A primeira é a construção do corpus de dados seguindo as três regras de exaustividade, representatividade e pertinência. Essas regras foram cumpridas antes da análise com o software, por meio da busca no banco de dados da BDTD. O Atlas.ti entra em cena a partir da leitura flutuante, pois sua interface permite organizar todos os documentos analisados em um contínuo, facilitando a leitura e a navegação entre documentos diferentes.

$\mathrm{Na}$ etapa de referenciação, o Atlas.ti é fundamental pois agiliza e otimiza o papel do pesquisador ao criar rapidamente os índices e seus indicadores através da função Code. Do mesmo modo, no processo de codificação das unidades de registro e contexto, o software permite explorar rapidamente todo o corpus, navegar entre pré-categorias, organizar os codes em grupos semelhantes (função Family) e gerenciar a análise através de mapas conceituais chamados de networks.

Como o software gera sempre um par ordenado do tipo x-y para indicar a frequência em que os dados foram destacados nos textos analisados, é possível proceder a análise quantitativa do percentual de itens, eliminar os que não são expressivos e dar continuidade com a categorização naqueles que se sobressaíram dentro do corpus. Também na função das networks, é possível criar mapas conceituais com matizes de cores, permitindo a rápida análise visual dos dados mais recorrentes.

Além disso, o Atlas.ti também permite exportar os dados em diversos formatos para serem trabalhados posteriormente, em outros computadores e até em outros programas. Também é possível gerar imagens das redes para utilização em processadores de texto e outros softwares, tornando a análise mais clara com as redes e as conexões entre elas.

A fim de conclusão, discutiremos brevemente os dados analisados sobre a robótica educacional que serviram como plano de fundo para explicitar como a etapa de tratamento, inferência e interpretação da Análise de Conteúdo pode ser facilitada após a análise dos dados no software. Para informações complementares sobre essa discussão, confira Silva Junior, Leão e Lins (2017). 
O software Atlas.ti como recurso para a análise de conteúdo: ...

Quadro 4. Processo de análise sistemática utilizando o Atlas.ti

\begin{tabular}{|c|c|c|c|}
\hline Objetivo & Método & \multicolumn{2}{|c|}{ Análise de Conteúdo } \\
\hline $\begin{array}{l}\text { Levantar no Banco de Teses } \\
\text { e Dissertações todas as teses } \\
\text { que discutam sobre robótica }\end{array}$ & $\begin{array}{l}\text { Coleta no banco de dados } \\
\text { utilizando a palavra-chave } \\
\text { "robótica" }\end{array}$ & $\begin{array}{l}\text { Escolha dos } \\
\text { documentos pela } \\
\text { regra da exaustividade }\end{array}$ & \multirow[t]{6}{*}{ Pré-análise } \\
\hline $\begin{array}{l}\text { Selecionar as teses que } \\
\text { apresentem conteúdo } \\
\text { relacionado à robótica } \\
\text { educacional }\end{array}$ & $\begin{array}{l}\text { Seleção a partir da leitura dos } \\
\text { títulos }\end{array}$ & $\begin{array}{l}\text { Escolha dos } \\
\text { documentos } \\
\text { pela regra da } \\
\text { representatividade } \\
\end{array}$ & \\
\hline $\begin{array}{l}\text { Filtrar as teses que tratem } \\
\text { do ensino de ciências }\end{array}$ & $\begin{array}{l}\text { Seleção a partir da leitura dos } \\
\text { resumos e inspeção do sumário }\end{array}$ & $\begin{array}{l}\text { Escolha dos } \\
\text { documentos pela } \\
\text { regra da pertinência }\end{array}$ & \\
\hline \multirow{7}{*}{$\begin{array}{l}\text { Analisar quantitativa e } \\
\text { qualitativamente as teses } \\
\text { selecionadas }\end{array}$} & $\begin{array}{l}\text { Leitura dos capítulos teóricos e } \\
\text { metodológicos }\end{array}$ & Leitura flutuante & \\
\hline & $\begin{array}{l}\text { Separação dos trabalhos a } \\
\text { partir das primeiras impressões }\end{array}$ & $\begin{array}{l}\text { Formulação de } \\
\text { hipóteses }\end{array}$ & \\
\hline & $\begin{array}{l}\text { Codificação de unidades de } \\
\text { registro (codes) e unidades } \\
\text { de contexto (quotations) } \\
\text { utilizando o software Atlas.ti }\end{array}$ & $\begin{array}{l}\text { Referenciação de } \\
\text { índices e indicadores }\end{array}$ & \\
\hline & $\begin{array}{l}\text { Associação de codes em } \\
\text { categorias (famílias) utilizando } \\
\text { o Atlas.ti }\end{array}$ & Codificação & \multirow{3}{*}{$\begin{array}{l}\text { Exploração } \\
\text { do material }\end{array}$} \\
\hline & $\begin{array}{l}\text { Construção da network (rede) } \\
\text { no Atlas.ti }\end{array}$ & \multirow[b]{2}{*}{ Categorização } & \\
\hline & $\begin{array}{l}\text { Elaboração de gráficos e } \\
\text { tabelas com base na frequência } \\
\text { das categorias }\end{array}$ & & \\
\hline & $\begin{array}{l}\text { Discussão das tendências } \\
\text { encontradas }\end{array}$ & & $\begin{array}{l}\text { Tratamento, } \\
\text { inferência e } \\
\text { interpretação }\end{array}$ \\
\hline
\end{tabular}

Fonte: elaborado pelos autores.

\section{Base epistemológica}

Identificamos o Construtivismo de Piaget e o Construcionismo de Papert como os principais arcabouços epistemológicos das teses analisadas. O construtivismo se apoia na ideia de trazer a robótica para a sala de aula como uma atividade lúdica. Já o construcionismo, segundo Bers et al. (2014, p. 46, tradução nossa), é uma variante do construtivismo de Piaget, no qual pontua que "crianças podem aprender profundamente quando elas constroem seus próprios projetos significativos em uma comunidade de aprendizes e reflete cuidadosamente nesse processo". Nesse viés, Ramírez e Sosa (2013, p. 52, tradução nossa) destacam que, na perspectiva construcionista "[...] quem aprende está particularmente motivado quando vive a experiência de construir - seja um robô, um artefato, um poema, um castelo de areia, um programa de computador ou uma teoria científica - sobre a qual podem refletir e compartilhar com outros" 
Dessa forma, as pesquisas que se apoiam no construcionismo buscam desenvolver projetos e colocar os estudantes como protagonistas.

\title{
Inconsistência metodológica
}

Nessa categoria elencamos os procedimentos metodológicos que ora nos parece trazer fraquezas ou inconsistências do ponto de vista entre teoria e prática. O primeiro ponto em destaque foi que 5 das 8 teses não discutem sobre a natureza qualitativa ou quantitativa da pesquisa, sendo esse um aspecto importante para distinguir trabalhos numa revisão sistemática de literatura.

Outra característica que nos parece frágil foi à triangulação dos dados somente através de questionários e observações para atingir os objetivos propostos. Entendemos a potencialidade desses instrumentos, mas pontuamos que, para o objetivo de avaliar em profundidade a construção do conhecimento em uma perspectiva construcionista somente esses dois instrumentos parecem ser insuficientes. Semelhante ponto de vista foi ressaltado por Benitti ao apresentar que existem vários fatores ligados ao aprender com robótica:

\begin{abstract}
Então, o que se pode dizer é que a robótica tem muito potencial para auxiliar no ensino, no entanto, o ganho em aprender pelos alunos não é garantido apenas pela simples aplicação da robótica, pois existem vários fatores que podem determinar o resultado. (BENITTI, 2012, p. 986, tradução nossa).
\end{abstract}

\section{Público-alvo}

Discutimos nessa categoria o principal locus onde as pesquisas foram realizadas, bem como os sujeitos envolvidos. A principal ênfase das 8 teses foram os estudantes da educação básica, o que nos permite inferir que o interesse principal dos autores é estudar a robótica na aprendizagem de conceitos científicos nos níveis fundamental e médio.

Uma discussão que já tem se consolidado na literatura internacional (ALIMISIS, 2013; BENITTI, 2012; KHANLARI, 2016) mas que se apresenta como incipiente nas teses brasileiras é a formação dos professores no que diz respeito ao uso da robótica.

\section{Características da produção nacional}

A última categoria vem descrever o panorama geral da produção brasileira sobre robótica educacional no ensino de ciências nas pesquisas desenvolvidas em nível de doutorado. Em termos de atividades didáticas desenvolvidas durante as pesquisas, as mais recorrentes foram oficinas e atividades extraclasse. A partir desse dado podemos interpretar que a falta de infraestrutura nas escolas públicas não permite ir além de intervenções pontuais com materiais trazidos da própria universidade.

Ao analisar os programas de pós-graduação em que as pesquisas foram desenvolvidas, percebemos destaque para a região sudeste e nordeste. Além disso, as teses brasileiras se demarcam historicamente com um atraso em relação à produção internacional. Segundo alguns autores (CHAVARRÍA; SALDAÑO MELLA, 2010; RAMÍREZ; SOSA, 2013), as primeiras discussões com robótica educacional ocorreram no início dos anos 90 do século XX, ao passo que a primeira tese brasileira foi produzida no ano de 2008. 


\section{Considerações finais}

O trabalho desenvolvido permitiu considerar o software Atlas.ti como um recurso propício para o desenvolvimento de todas as etapas da Análise de Conteúdo de Bardin, facilitando o trabalho do analista e contribuindo para o estabelecimento de relações que culminam no tratamento e inferência dos resultados.

Foi possível desenvolver as três etapas da AC (pré-análise, exploração e tratamento) com o suporte do software, de forma que o trabalho manual foi reduzido substancialmente e o tempo gasto com a referenciação e codificação foi otimizado, permitindo aos pesquisadores se debruçarem melhor nas análises posteriores.

O software Atlas.ti é uma importante ferramenta para pesquisadores de diversas áreas, pois possui uma gama de recursos que permite seu uso em inúmeras áreas do conhecimento, além de possuir uma interface que propicia a análise de diversos tipos de dados para garantir o cumprimento de toda sorte de objetivos. Contudo, como foi bem salientado, o software otimiza o trabalho mas não faz a análise sozinho. Todas as correlações e análises são conduzidas pelo analista a partir de seu referencial teórico e de sua compreensão dos dados.

Como plano de fundo para orientar o trabalho de análise no software, conduzimos uma análise sistemática da literatura de teses brasileiras sobre a robótica educacional no ensino de ciências. Ainda que não fosse o objetivo central desse artigo, conseguimos compreender e discutir alguns aspectos da produção nacional, tal como a abordagem epistemológica utilizada nas teses, o público-alvo das pesquisas, as fragilidades metodológicas e as características da produção brasileira de modo geral.

Diante das categorias discutidas, é coerente apontar que a robótica educacional é um tema relevante para pesquisas, uma vez que existe baixa produção, grupos de pesquisa ainda não consolidados e detalhes que precisam ser mais bem explicitados, sobretudo os referenciais teóricos e metodológicos.

Por fim, salientamos que o objetivo ora proposto foi satisfatoriamente alcançado e o Atlas.ti se mostrou uma importante ferramenta para pesquisadores conduzirem suas pesquisas qualitativas à luz da Análise de Conteúdo de Bardin.

\section{Referências}

ALIMISIS, D. Educational robotics: open questions and new challenges. Themes in

Science and Technology Education, Ioannina, v. 6, n. 1, p. 63-71, 2013.

BARDIN, L. Análise de conteúdo. Lisboa: Edições 70, 1970.

BENITTI, F. B. V. Exploring the educational potential of robotics in schools: A systematic review. Computers \& Education, New York, v. 58, n. 3,p. 978-988, 2012.

BERS, M. U. et al. Computational thinking and tinkering: exploration of an early childhood robotics curriculum. Computers \& Education, New York, v. 72, p. 145-157, 2014. 
BRANCO, W. C. O software educacional na prática docente: um olhar da teoria da atividade. Em Teia: revista de educação matemática e tecnológica iberoamericana, Recife, v. 2, n. 3, p. 1-25, 2011. Disponível em: <https://periodicos.ufpe.br/revistas/emteia/article/ view/2178/1749>. Acesso em: 20 ago. 2018.

CHAVARRÍA, M.; SALDAÑO MELLA, A. La robótica educativa como una innovativa interfaz educativa entre el alumno y una situación-problema. Didasc@lia: didáctica y educación, La Havana, n. 2, p. 1-12, 2010. Disponível em: <https://dialnet.unirioja.es/ servlet $/$ revista?codigo=16083>. Acesso em: 20 ago. 2018.

HWANG, S. Utilizing qualitative data analysis software: a review of Atlas.ti. Social Science Computer Review, Thousand Oaks, v. 26, n. 4, p. 519-527, 2008.

KHANLARI, A. Teachers' perceptions of the benefits and the challenges of integrating educational robots into primary/elementary curricula. European Journal of Engineering Education, London, v. 41, n. 3, p. 320-330, 2016.

MUHR, T. ATLAS.ti: a prototype for the support of text interpretation. Qualitative Sociology, New York, v. 14, n. 4, p. 349-371, 1991.

RAMÍREZ, P. A. L.; SOSA, H. A. Aprendizaje de y con robótica, algunas experiencias. Revista Educación, San Jose, v. 37, n. 1, p. 43-63, 2013. Disponível em: <https://doi. org/10.15517/revedu.v37i1.10628>. Acesso em: 20 ago. 2018.

\section{SILVA, E. R. P. Métodos para revisão e mapeamento sistemático da literatura.}

2009. 131 f. Trabalho de conclusão de curso (Graduação em Engenharia de Produção Universidade Federal do Rio de Janeiro, Rio de Janeiro, 2009.

SILVA JUNIOR, L. A.; LEÃO, M. B. C.; LINS, W. C. B. A robótica educacional no ensino de ciências em teses de doutorado brasileiras. Enseñanza de Las Ciencias, Barcelona, n. extra., p. 749-754, 2017. Disponível em: <http:/ /www.raco.cat/index.php/Ensenanza/ article/download/335360/426188>. Acesso em: 20 ago. 2018.

Artigo recebido em 15/07/2017. Aceito em 17/02/2018. 